\title{
Going Green with Policy Incentives: \\ Comparing the Use of Subsidies and Taxes to Reduce Transportation Emissions
}

Miranda Hines

his article addresses the need for the United States to reduce emissions from the transportation sector. In order to concisely evaluate the political discussion of promoting renewable energy use and discouraging reliance on fossil fuels, this article focuses on the adoption of electric and hybrid vehicles as a means of illustrating the larger policy challenge of how to maximize policy effectiveness at reducing emissions while minimizing economic disruption. The article estimates the magnitude of electric and gas-powered vehicles purchases in response to either a subsidy or a tax and discusses the positive and negative outcomes of each policy approach. The article finds that while a tax on carbon emissions may be most effective in removing gas-powered vehicles from the road, it will disproportionately affect lower-income households. Implementing substantial subsidies for electric vehicles, funded through a smaller tax on carbon emissions, is suggested as a solution to reduce the regressive impacts of a standalone carbon tax. 


\section{INTRODUCTION}

Finding ways to mitigate the drivers of climate change is among the most significant challenges faced by the global community in the twenty-first century. While climate change is usually discussed in terms of environmental stewardship-it is a negative outcome because it is damaging to both the natural world and human health and safety-climate change can also be understood through an economic lens. Economists generally view climate change as a market failure, meaning that climate change is a problem not because it is harmful per se; it is a problem because the populations harmed by pollution are often not participants in the activities and transactions that generated it in the first place. As a result, international governments have an economic responsibility to address climate change as a market failure and use policies to correct for it.

This article begins with a brief discussion of climate change and the need for a transition to renewable energy. Using existing markets for gas and electric cars as an example, the article subsequently explores the economic theories that drive the effectiveness of renewable energy subsidies and a price on carbon emissions, in the form of taxes on $\mathrm{CO} 2$ emitters. The article continues with a brief discussion of the policies' respective limitations and requirements to be effective at reducing emissions in a manner that is palatable to consumers and politicians. The results of this article's elasticity calculations indicate that both electric car subsidies and taxes on gas-powered vehicles have the potential to shift consumer behavior toward more renewable practices; of the two, taxes have a greater impact on the reduction of gas-powered vehicle purchases. The effective implementation of both policies requires awareness for how each policy will affect welfare and incentivize behavior across income groups.

\section{CLIMATE CHANGE AND POLICY ALTERNATIVES}

Imagine there are three parties within a single market for air travel: person $\mathrm{A}$, who has never taken a flight; person B, who flies regularly; and C, the airline. Even though person A has never flown, A still experiences the environmental impacts of the $\mathrm{CO} 2$ released by the transaction between person $\mathrm{B}$ as the consumer and airline $\mathrm{C}$ as the supplier. In economic terms, $\mathrm{A}$ is experiencing a negative externality, or a negative side-effect of a transaction they did not participate in. Climate change can be viewed as a negative externality due to the imbalance between parties directly involved in transactions and the negative effects borne by parties absent from these transactions.

This theory is readily observable in the real world. The effects of climate change are dispersed across the globe, and the communities that suffer the brunt of the changing environmental landscape are often not among those who generated the pollution and environmental degradation to start with. For example, many small, rural villages in Mozambique were leveled by Cyclone Idai in March 2019. While the individual cyclone was not necessarily caused by climate change, the disaster was more severe than historical norms would suggest due to rising temperatures and flooding driven by climate change (Gavin 2019; WMO 2019).

This externality could indicate a market failure, meaning there are no market-based solutions and policy intervention may be able to correct it. Market failures can also indicate 
an absent but necessary market; for example, a market for carbon capture technologies could address the externality as well. However, given that a market for carbon-capture technologies does not presently exist, government regulation is necessary to address or mitigate the negative consequences of climate change by an alternative price-based economic mechanism. A pricebased mechanism is a form of regulation designed to internalize the negative externality, therefore economically accounting for the harm incurred (Bowen 2012).

The international community has widely agreed to a global warming limit of 1.5 degrees Celsius, recognizing that temperatures beyond this point will have increasingly severe and negative consequences for humanity and the planet (Allen et al. 2018). One approach to slowing the rate of climate change is to decrease carbon emissions through the reduction of fossil fuel consumption, which is currently the largest contributing factor to global warming (Quéré et al. 2019; Cansino et al. 2010).

Energy sources are broadly categorized as one of three types: fossil fuels, renewable energy, and nuclear power. The fossil fuels category includes coal, natural gas, and petroleum. The renewable energy category includes hydroelectric power, geothermal energy, solar power, wind power, and biomass. The vast majority of energy consumed both at the national and international level is derived from fossil fuels. For example, 78 percent of the energy consumed within the United States in 2017 came from fossil fuels, while just 11 percent came from renewable energy sources (EIA 2018, Table 1.3). Broadly speaking, there are two non-exclusive policy approaches to reducing fossil fuel emissions: make fossil fuel emissions costlier through a tax on carbon emissions, or make renewable energy sources less costly through subsidies. A tax on the purchase of a gas-powered car is an example of the former and a subsidy for the purchase of an electric vehicle is an example of the latter; both are designed to reduce emissions, but through opposing incentives.

\section{ECONOMIC THEORY: TRANSPORTATION EXAMPLE}

This section of the article focuses on how consumers respond to subsidies and taxes, using existing markets for electric vehicles and traditional gas-powered vehicles as an example. The United States Environmental Protection Agency (EPA) estimates approximately 29 percent of greenhouse gas emissions are produced through transportation and recommends a transition to electric and hybrid vehicles to combat this, conditional on successfully converting the energy grid that powers them to renewable energy sources (EPA 2019). The EPA likewise estimates the average car emits approximately 4.6 metric tons of $\mathrm{CO} 2$ per year, and 8,887 grams of CO2 are emitted per gallon of gasoline burned (EPA 2018). Given these facts, a critical element of reducing carbon emissions in the United States is the overhaul of the US' current transportation system. In addition to promoting the use of public transportation and emission-free options such as bicycling and walking, reducing emissions is contingent on moving away from a fossil fuel-dependent transportation system.

\section{HOW SUBSIDIES AND TAXES AFFECT THE MARKET}

Subsidies are designed to make a good relatively less expensive for consumers to purchase by either reducing companies' production costs or by directly reimbursing consumers for the purchase. If the government subsidizes electric vehicle production, the companies that 
manufacture the vehicles internalize a portion of the economic benefit before transferring the remaining benefit on to consumers in the form of lower prices. The effect of subsidizing electric vehicle production is shown in Figure 1a.

Figure 1. Economic Theory of Market Responses

1a. Electric Vehicle Subsidy:

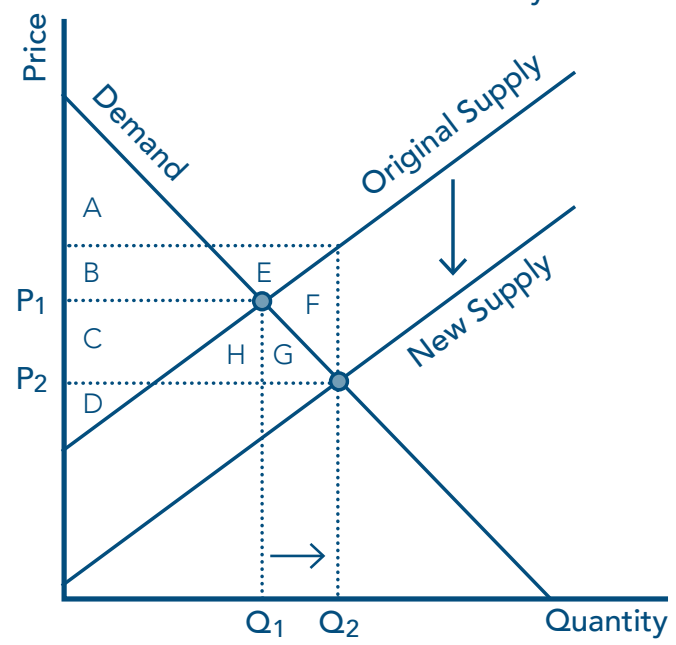

1b. Tax on Gas-Powered Cars:

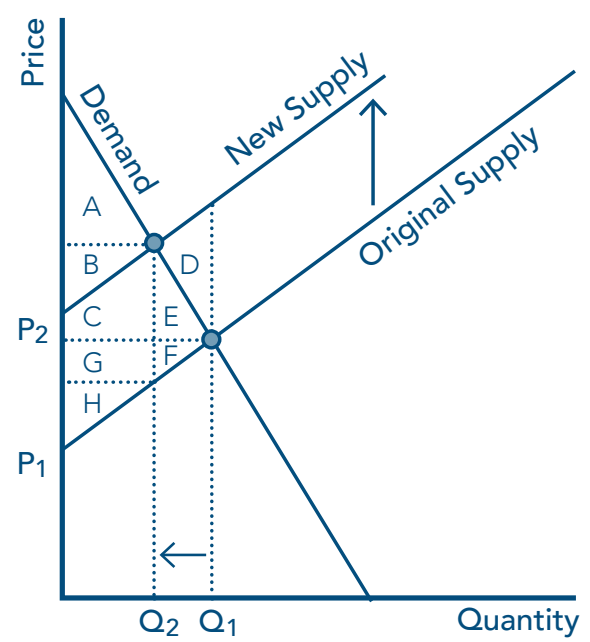

In the absence of the subsidy, consumer surplus-the aggregate consumer welfare, meaning the difference between what customers actually pay and what they are willing to pay for a good-is represented by area AB in Figure 1a. Producer surplus-the aggregate producer welfare, which is the difference between the price suppliers would be willing to sell the good for and the price the good actually sells for-includes area CD. After the introduction of the subsidy, the market price for electric vehicles decreases from P1 to P2 and the quantity demanded by consumers increases from Q1 to Q2.

Both consumers and producers are better off, as their respective surpluses become equivalent to ABCHG and DCBE following the implementation of the policy. However, the market as a whole is worse off due to the expense born by the government; the amount that the government pays to fund the subsidy, represented by BEFGHC, is larger than the combined increase in welfare experienced by producers and consumers. Looking exclusively at this transaction (i.e., without considering the correction of the externality and anticipated environmental benefit), the existence of the subsidy renders the market worse off as a whole.

While a subsidy makes electric vehicles comparatively less expensive in order to encourage consumption, a tax on gasoline-powered vehicles discourages consumption by making them relatively more expensive. The government could place a tax on manufacturers producing gas-powered vehicles with the goal of reducing emissions by increasing the price of the cars. This will deter customers from purchasing the cars and, by extension, reduce the consumption of gasoline. Much of the tax burden will fall on the companies themselves; however, the companies will also raise the price of vehicles to partially shift the tax burden to their customers. The effect of a tax on the production of gas-powered vehicles is shown in Figure $1 b$. 
In the absence of the tax, the consumer surplus includes the region $\mathrm{ABCE}$, and the corresponding producer surplus includes the region GHF. The region CDEFGH represents the negative externality, which is an economic estimate of the harm inflicted by vehicle emissions. Essentially, this graph reflects a disparity between the value consumers would assign to driving gas-powered vehicles based solely on their private use (P1) and the value consumers would assign to driving gas-powered vehicles if they included both their private use and the effects of its emissions on the broader public (P2). A significant policy challenge of implementing a carbon tax is identifying what the difference between P1 and P2 is; this model assumes perfect information, which would allow the carbon tax to be set at the correct value.

Introducing a tax on the production of gas-powered cars would increase the purchase price of the vehicles, resulting in a decrease in the number of gas-powered cars purchased from Q1 to Q2 in Figure 1b. It is important to note that, in terms of private welfare, the tax seems to leave both producers and consumers worse off-consumer welfare is represented by $\mathrm{ABCE}$ prior to the tax and is reduced to A post-tax, while produce welfare is represented by GHF prior to the tax and reduced to $\mathrm{H}$ post-tax. This is because the tax creates a deadweight loss (region EF) and transfers some of the consumer and producer surpluses into government revenue (region BCG). However, the harm generated by purchasing and driving gas-powered vehicles is substantially reduced with the tax; it is now represented by region $\mathrm{D}$.

While the private market now has a deadweight loss, from a public goods perspective the tax reduces the harm experienced as a result of vehicle emissions. The negative externality has been internalized, meaning that the cost generated by the externality has been shifted from non-participants to the participants of the transaction. Continuing with the introductory airplane example in which flight-taker B generates emissions that harm nonflier A, placing a tax on flying results in person B essentially paying for the harm experienced by person A.

\section{HOW AN ELECTRIC VEHICLE SUBSIDY WILL AFFECT INDIVIDUAL CONSUMER BEHAVIOR}

Subsidies drive consumer behavior differently depending on whether the subsidy amount is small or large relative to how much of the renewable energy source was already being consumed, as shown in Figure 2. In concrete terms, say there are two consumers with the same budget constraint of $\$ 60,000$ - meaning they could spend a maximum of $\$ 60,000$

Figure 2. Economic Theory of Consumer Behavior with a Subsidy

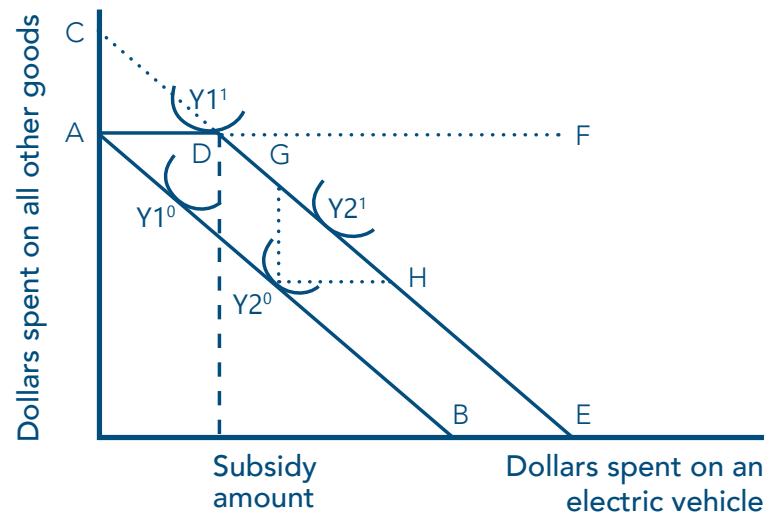

on an electric vehicle if they consume no other goods (point B), or they could spend no money on an electric vehicle and consume $\$ 60,000$ worth of other goods (point A). Both consumers will opt to consume somewhere on the line $\mathrm{AB}$ according to their personal preferences; in this example, the first costumer initially consumes at indifference curve $\mathrm{Y} 10$ and the second customer initially consumes at indifference curve $\mathrm{Y} 2^{0}$. 
$\mathrm{Y} 1^{0}$ indicates the first consumer is willing to spend less than the subsidy amount in the policy's absence. If the subsidy is $\$ 20,000$ and the consumer is willing to spend a maximum of $\$ 10,000$ on an electric vehicle, then the first consumer has a new budget; it is possible to spend either $\$ 60,000$ on all goods other than the electric car, or to take advantage of the subsidy and purchase an electric car worth $\$ 80,000$ using the consumer's $\$ 60,000$ budget plus the subsidy. The subsidy therefore acts as a change in the price of an electric vehicle. The consumer's budget line rotates from $\mathrm{AB}$ to $\mathrm{AF}$ for all car values below the subsidy and from line $\mathrm{AB}$ to line $\mathrm{DE}$ for all values above the subsidy amount. The consumer's new optimal consumption bundle $\mathrm{Y} 1^{1}$ is likely at the budget line kink (point D). At this point, the consumer will spend exactly the subsidy amount on an electric vehicle and will spend their $\$ 60,000$ income on all other goods.

In contrast, $\mathrm{Y} 2^{0}$ indicates that the second consumer is willing to spend more than the subsidy amount in the policy's absence-this individual is willing to spend $\$ 40,000$ on an electric vehicle. Because the subsidy is less than what the consumer was initially willing to spend, the subsidy acts as an increase in real income rather than a price change. This shifts the second consumer's budget from line $\mathrm{AB}$ to line $\mathrm{CE}$; however, because the consumer can only receive the subsidy if an electric car is purchased, the consumer can effectively only afford allocations on line DE. The second consumer's new optimal consumption point $\mathrm{Y}^{1}$ will fall on the line DE between points $G$ and $H$.

\section{HOW A TAX ON GAS-POWERED CARS WILL AFFECT INDIVIDUAL CONSUMER BEHAVIOR}

Taxes are designed to deter consumption by making a good relatively more expensive, as shown in Figure 3. Suppose a consumer has a budget constraint of $\$ 60,000$, represented by line AE. As in the previous subsidy example, the consumer can spend at most $\$ 60,000$ on a gas-powered car if nothing else is purchased (point $\mathrm{E}$ ) or $\$ 60,000$ on everything other than the car (point A). The consumer's optimal purchase is a combination of the two located at $\mathrm{Y}^{0}$.

Following the implementation of the tax, the consumer's budget constraint will rotate inwards from $\mathrm{AE}$ to $\mathrm{AB}$ as the gas-powered car becomes relatively more expensive. The consumer will likely optimize at $\mathrm{Y} 1^{1}$. This means the consumer is willing to spend less on a gaspowered car and less on all other goods in the short term, assuming that individual still opts to purchase a gas-powered car. In the long term, the consumer has greater ability to pursue transportation alternatives that are relatively more affordable and produce lower emissions.

\section{SUBSTITUTES AND ELASTICITY OF DEMAND}

Both subsidies and taxes depend on customers' responsiveness to price in order to be effective. This article assumes electric and gas-powered cars are substitutes, meaning an
Figure 3. Economic Theory of

Consumer Behavior with a Tax

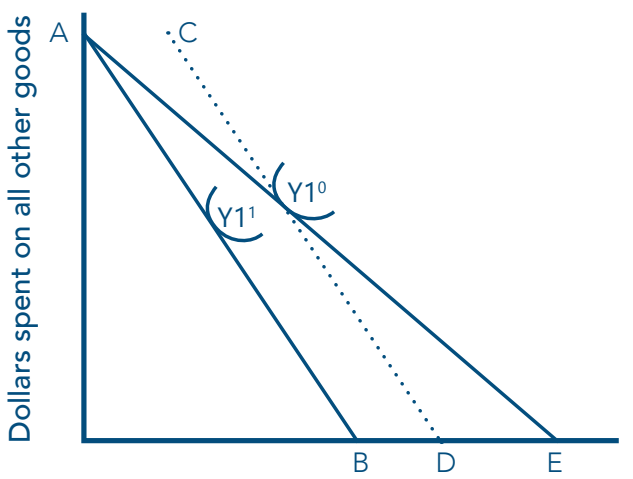

Dollars spent on an electric vehicle 
individual looking to purchase a car would be willing to consider either option and would be responsive to price incentives designed to encourage the purchase of an electric vehicle instead of a gas-powered car. Own-price elasticity refers to the change in quantity demanded of a good given a percent change in the price of that good. Cross-price elasticity refers to the change in quantity demanded of a good given a percent change in the price of a substitute for that good.

Research on the elasticity of demand for electric and gas-powered cars, which measures how demand changes for one vehicle type in response to a change in the price of the other, is limited. A study by Xing, Leard, and Li (2019) comparing the price elasticities of ten vehicles including gas-powered cars, battery-powered electric vehicles (BEVs), standard hybrid electric vehicles (HEVs), and plug-in hybrid electric vehicles (PHEVs). The study found that average own-price elasticity of demand for the gas-powered vehicle sample was -2.87 and the average cross-price elasticity was 0.05 , while the average own-price elasticity of demand for the electric vehicle sample was -2.64 and the average cross-price elasticity was 0.03 (Xing, Leard, and Li 2019, 34). In a hypothetical market in which consumers want to purchase 100,000 of each type of vehicle, the following would be expected to occur: a 25 percent increase in the price of gas-powered vehicles due to a tax would result in consumers purchasing 71,850 fewer gas-powered vehicles and 1,260 additional electric vehicles relative to the no-policy counterfactual, while a 25 percent decrease in the price of electric vehicles due to a subsidy would result in consumers purchasing 740 fewer gas-powered vehicles and 66,050 additional electric vehicles relative to the no-policy counterfactual.

The real-world numbers will vary depending on the size of the tax or subsidy implemented. However, these results suggest that both subsidies for electric vehicles and taxes to increase the price of gas-powered vehicles can shift consumer demand toward electric vehicles, but that the larger effect would occur with respect to consumer demand for the type of car directly affected by the regulation. From an economic theory standpoint, taxes affect behavior across the entire market and have the potential to change a larger number of consumers' behavior; because subsidies are optional, their effectiveness is only as good as the rate of participation.

\section{DISCUSSION}

This section aims to evaluate both policies in their real-world applications, and expands on the vehicle discussion to include renewable energy subsidies and taxes on carbon emitters more broadly. Arguably, the weakest aspect of renewable energy subsidies is that they offer a reward but do not force changes in consumption patterns. Additionally, subsidies require government funding, which means they may remain politically unfeasible even if they are effective. Likewise, a major limitation of the carbon tax is how the burden of the tax is distributed. Even if the government has sufficient information to accurately set a price either directly on emissions or on purchases that contribute to emissions, the price with the tax added may be high enough that consumers actively oppose the policy because the impact it has on their immediate welfare is intolerable.

\section{ARE SUBSIDIES ECONOMICALLY FEASIBLE?}

Subsidies require funding, which in turn requires government revenue. Funding a subsidy would require the government to either spend less on other services and provisions or raise taxes. Subsidies may be economically feasible, but they may not be politically feasible if the 
mechanism by which they are funded lacks sufficient public support. Looking at emissions reduction targets broadly, a study comparing the relative cost of implementing renewable energy subsidies and implementing a tax on carbon to achieve the same reduction in emissions found that subsidies are the higher-cost policy. Making renewable energy sources cheap and accessible enough to radically decrease fossil fuel consumption is a substantial investment (Gerlagh and van der Zwaan 2006, 36-37).

\section{ARE CONSUMERS RESPONSIVE TO SUBSIDIES IN ACTUALITY?}

Economic theory suggests subsidies benefit individuals who spend more than the subsidy amount to a greater degree than individuals who spend less than the subsidy amount in its absence; this implies individuals who are most likely to take advantage of the subsidy have relatively high incomes. As a result, subsidies have the potential to be economically regressive policies. There is evidence to support this concern. In 2012, the Congressional Budget Office (CBO) conducted an evaluation of the federal income tax credit for electric vehicles, which functions akin to a subsidy, and found an estimated 70 percent of the electric vehicles purchased would have been purchased in the absence of the subsidy (CBO 2012, 15). In other words, the subsidy benefits individuals with relatively high incomes who are already motivated to reduce their carbon footprint, rather than actually changing consumer behavior by encouraging individuals who would not otherwise have purchased an electric vehicle to do so (CBO 2012, 15).

A subsequent study by Li et al. (2017) found similar results-an estimated 60 percent of electric vehicles would have been purchased in the absence of the subsidy (Table 9). This reflects the limitation of subsidies as incentives; participation is optional, and if the value of the subsidy is low relative to the price of the good, it will not necessarily change patterns of consumption. In the United States, the current value of the electric car subsidy is too far below the price of the vehicles to result in a radical transition.

\section{WILL SUBSIDIES DECREASE EMISSIONS?}

All fully electric vehicles produce zero direct emissions, and PHEVs produce fewer emissions than traditional gas-powered cars (DOE 2019). However, the absence of tailpipe emissions does not translate to a clean carbon footprint. Research suggests if an electric company supplies energy to a community that is derived from a portfolio including both fossil fuels and renewable sources, and if the company receives a subsidy for renewable energy generation, then consumers will respond to the lower price of energy by consuming more energy. However, because the portfolio is mixed, the increase in energy consumption will include increased consumption of both the renewable energy and the fossil-fuel derived energy (Murray et al. 2014, 571-573). This is particularly relevant regarding the transition to an electrified transportation fleet; electric vehicles do not eliminate emissions if they are powered by electricity generated by burning fossil fuels (EPA 2019).

\section{IS A TAX-BASED APPROACH TO REDUCING EMISSIONS EQUITABLE?}

Research conducted by the Centre for Climate Change and Economics Policy and the Grantham Research Institute on Climate Change and the Environment identified two key reasons that the public is averse to carbon taxes: concerns that personal costs would be too 
high, and that the taxes would be regressive, meaning that lower-income households would pay disproportionately more of their income in these taxes (Bassi et al. 2017, 7). A case study on the carbon tax in France, which applies to gasoline and other $\mathrm{CO}_{2}$ emitters, found evidence to support concerns that emissions taxes are economically regressive (Berry 2019). The economic impact of the carbon tax was nearly three times greater on the poorest ten percent of the country than the wealthiest ten percent due to the difference in tax to income ratio (85).

In addition, the rising cost of energy increased the number of French citizens in fuel poverty-defined as households spending ten percent or more of income on energy (CGDD, 2016, as cited in Berry 2019, 84) - by 200,000 individuals (86). In addition to spending proportionately more of their income on energy, low-income consumers likely also have fewer opportunities to transition to more environmentally-friendly options; buying a more fuel-efficient vehicle or an electric car requires a level of disposable income that many may not have even before the implementation of the carbon tax.

\section{IF A TAX TO REDUCE EMISSIONS IS NOT INHERENTLY FAIR, CAN IT BE MADE SO?}

A unilateral tax on gas-powered cars, or a tax on carbon emissions overall, is not designed to be income-sensitive or sensitive to variations in transition costs. If a tax is implemented, an approach to equalizing the burden of the policy would be to use the tax revenue to benefit those individuals hurt most by the tax. This could be done by reducing the income tax owed by individuals living in fuel poverty, or by providing additional funding for goods and services that allow them to reduce their non-fuel expenditures. If the bulk of the tax burden were incurred by industries, the tax revenue could be used to reduce corporate income tax. Additionally, a carbon tax could be used to increase the subsidy amount for electric vehicles to promote the transition to an electrified transportation fleet.

\section{POLICY IMPLICATIONS AND CONCLUSIONS}

Literature on the relationship between the policies and real-world consumer responses suggest that both policy alternatives are viable options for reducing emissions from gaspowered vehicles in the United States, but neither policy is an environmental silver bullet. To be effective, subsidies need to be sufficiently high to change the behavior of middle- and lowincome households; if they are too low, they merely act as financial rewards for higher-income households that would likely have purchased electric vehicles in the absence of a subsidy. Alternatively, a tax on gas-powered cars would indirectly decrease fossil fuel consumption and avoids the participation dilemma that characterizes subsidies, but the financial burden can be inequitable based on the country's socioeconomic stratification.

Assuming that the primary policy goal is to directly address climate change as a negative externality, a tax is the more effective policy; while subsidies encourage consumers to purchase more electric vehicles, they do not directly correct for the externality in the market. However, if the policy is implemented broadly as a tax on all carbon emissions, it is also the considerably more disruptive option. The backlash in France against higher fuel prices reflects that policymakers need to successfully convince the public to support something that will cost them in the short term in order to achieve a long-term benefit they may never see, otherwise carbon pricing policy will fail. Policymakers face a significant challenge: they must minimize 
the short-term costs to the public while still implementing policy aggressive enough to meet emissions reduction targets.

For this reason, complementing a carbon emissions tax by subsidizing renewable energybased means of transportation may be a viable approach to maximizing the effectiveness of the tax by minimizing the cost to consumers. This would also likely reduce the political backlash triggered by the tax. Using the government revenue generated by the tax, transportation subsidies could be implemented to make low and zero-emission alternative means of transportation more affordable for low-income households. An alternative to relying on subsidies to reduce the burden would be to reduce income taxes by the amount of revenue generated by the carbon tax, stratified to benefit low-income households to the greatest extent. There are likely other alternatives to making the policies tolerable to the public, but the literature and economic theory suggest that in order to reduce transportation emissions and address climate change as a negative externality, a price on carbon will be effective without subsidizing renewable energy, but a subsidy will not be as effective as a stand-alone policy as a tax on carbon would be. 


\section{REFERENCES}

Allen, M.R., O.P. Dube, W. Solecki, F. Aragón-Durand, W. Cramer, S. Humphreys, M. Kainuma, J. Kala, N. Mahowald, Y. Mulugetta, R. Perez, M. Wairiu, and K. Zickfeld. 2018. "Framing and Context." In: Global Warming of $1.5^{\circ} \mathrm{C}$. An IPCC Special Report on the impacts of global warming of $1.5^{\circ} \mathrm{C}$ above pre-industrial levels and related global greenhouse gas emission pathways, in the context of strengthening the global response to the threat of climate change, sustainable development, and efforts to eradicate

poverty [Masson-Delmotte, V., P. Zhai, H.-O. Pörtner, D. Roberts, J. Skea, P.R. Shukla, A. Pirani, W. Moufouma-Okia, C. Péan, R. Pidcock, S. Connors, J.B.R. Matthews, Y. Chen, X. Zhou, M.I. Gomis, E. Lonnoy, T. Maycock, M. Tignor, and T. Waterfield (eds.)].

Bassi, Samuela, Maria Carvalho, Baran Doda, and Sam Frankhauser. 2017. "Decarbonising the European Union Credibly, Effectively and Acceptably." Issue brief. Decarbonising the European Union Credibly, Effectively and Acceptably. Grantham Research Institute on Climate Change and the Environment and the Centre for Climate Change and Economics Policy. http://www.lse. ac.uk/GranthamInstitute/wp- content/uploads/2017/12/Decarbonising-the-European-Unioncredibly-effectively-and- acceptably-1-1.pdf.

Berry, Audrey. 2019. “The Distributional Effects of a Carbon Tax and Its Impact on Fuel Poverty: A Microsimulation Study in the French Context." Energy Policy 124 (January): 81-94. http://proxygw.wrlc.org/login?url=http://search.ebscohost.com/login.aspx?direct=true\&d $\mathrm{b}=\mathrm{ecn} \& \mathrm{AN}=1748290 \&$ site $=$ ehost-live.

Bowen, Alex. 2012. "What is a Carbon Price and Why Do We Need One?" The Guardian and The Grantham Research Institute on Climate Change and the Environment. July 16, 2012. https:// www.theguardian.com/environment/2012/jul/16/carbon-price-tax-cap.

Cansino, Jose M., Maria Del P. Pablo-Romero, Rocio Roman, and Rocio Yniguez. 2010. “Tax Incentives to Promote Green Electricity: An Overview of EU-27 Countries." Energy Policy 38, no. 10 (October): 6000-6008. https://doi.org/10.1016/j.enpol.2010.05.055.

CBO (Congressional Budget Office). 2012. Effects of Federal Tax Credits for the Purchase of Electric Vehicles. https://www.cbo.gov/sites/default/files/112th-congress-2011-2012/reports/09-20-12electricvehicles0.pdf.

CGDD (Commissariat Général au Développement Durable). 2015. Les indicateurs de la précarité énergétique en France. https://www.cairn.info/revue-francaise-d-economie-2015-4-page-187.htm.

DOE (US Department of Energy). 2019. Reducing Pollution with Electric Vehicles.

https://www.energy.gov/eere/electricvehicles/reducing-pollution-electric-vehicles.

EIA (US Energy Information Administration). 2018. Monthly Energy Review: December 2018. EIA. https://www.eia.gov/totalenergy/data/monthly/archive/00351812.pdf.

EPA (US Environmental Protection Agency). 2018. Greenhouse Gas Emissions from a Typical Passenger Vehicle. EPA. https://www.epa.gov/greenvehicles/greenhouse-gas-emissions-typical-passengervehicle.

---. 2019. Sources of Greenhouse Gas Emissions. EPA. https://www.epa.gov/ghgemissions/sourcesgreenhouse-gas-emissions\#transportation.

Gavin, Michelle. 2019. "Cyclone Idai and the New Reality of Climate Change in Africa." Council on Foreign Relations, March 29, 2019. https://www.cfr.org/blog/cyclone-idai-and-new-realityclimate-change-africa. 


\section{Featured Articles}

Gerlagh, Reyer and Bob van der Zwaan. 2006. "Options and Instruments for a Deep Cut in CO2 Emissions: Carbon Dioxide Capture Or Renewables, Taxes Or Subsidies?” The Energy Journal 27 (3): 25-48.

Kalkuhl, Matthias, Ottmar Edenhofer, and Kai Lessmann. 2013. "Renewable Energy Subsidies: SecondBest Policy or Fatal Aberration for Mitigation?" Resource and Energy Economics 35 (3): 217-234. https://doi.org/10.1016/j.reseneeco.2013.01.002.

Li, Shanjun, Lang Tong, Jianwei Xing, and Yiyi Zhou. 2017. “The Market for Electric Vehicles: Indirect Network Effects and Policy Design." Journal of the Association of Environmental and Resource Economists 4 (1): 89-133. https://doi.org/10.1086/689702.

Murray, Brian C., Maureen L. Cropper, Francisco C. de la Chesnaye, and John M. Reilly. 2014. "How Effective Are US Renewable Energy Subsidies in Cutting Greenhouse Gases?” American Economic Review 104 (5): 569-74. https:doi.org/10.1257/aer.104.5.569.

Quéré, Corinne Le, Jan Ivar Korsbakken, Charlie Wilson, Jale Tosun, Robbie Andrew, Robert J. Andres, Josep G. Canadell, Andrew Jordan, Glen P. Peters, and Detlef P. van Vuuren. 2019. "Drivers of Declining CO2 Emissions in 18 Developed Economies." Nature Climate Change 9 (3): 213-17.

Xing, Jianwei, Shanjun Li, and Benjamin Leard. 2019. What Does an Electric Vehicle Replace? Working paper 19-05. Resources for the Future. https://media.rff.org/documents/WP_19-05_Leard.pdf.

WMO (World Meteorological Association). 2019. Mozambique Cyclones Are "Wake-Up Call," Says WMO. WMO. https://public.wmo.int/en/media/press-release/mozambique-cyclones-are$\% \mathrm{E} 2 \% 80 \% 9$ Cwake-call\%E2\%80\%9D-says-wmo. 
MIRANDA HINES is a second-year Master of Public Policy Student (MPP) candidate at the Trachtenberg School, focusing on environmental policy and program evaluation. Originally from Akron, Ohio, Miranda graduated cum laude from Washington University in St. Louis in 2017 with a BA in political science and English literature. Prior to enrolling in graduate school, she was a Team Assistant at PricewaterhouseCoopers, LLP in Columbus, Ohio. She is currently a Teaching Assistant and Graduate Research Assistant for the Trachtenberg School. During her free time, she enjoys baking, riding her bike, and exploring DC's museums.

\section{ACKNOWLEDGEMENTS}

The author would like to thank her incredibly enthusiastic and dedicated editorial team, Professor Peter Linquiti, Associate Editor Stephanie Silver, and Editor-in-Chief Kendall Banks for their comments and suggestions. She also sends a sincere thank you to Professor Anil Nathan for his helpful feedback and support over the course of the paper's evolution. In the absence of the editorial team's encouragement and advice, this paper would not be where it is today. 